\title{
PENINGKATAN KEMAMPUAN PEMECAHAN MASALAH FISIKA SISWA MENGGUNAKAN METODE PRAKTIKUM DI KELAS X MAN SIPIROK
}

\author{
Elisa $^{1)}$, Ainun Mardiyah ${ }^{1)}$, Aslamiyah Rambe ${ }^{1)}$ \\ ${ }^{1)}$ Program Studi Pendidikan Fisika, FKIP, Universitas Muhammadiyah Tapanuli Selatan, Indonesia \\ e-mail: elisa@um-tapsel.ac.id
}

\begin{abstract}
Abstrak
Penelitian ini bertujuan untuk meningkatkan kemampuan pemecahan masalah Fisika dan hasil belajar siswa pada materi Kinematika Gerak Lurus dengan kemampuan awal menggunakan metode praktikum biasa dan metode praktikum dengan prosedur berbeda. Penelitian ini adalah penelitian Tindakan Kelas (PTK) dengan 2 siklus. Subyek penelitian ini adalah kelas X MIA 2 MAN Sipirok yang masing-masing kelas berjumlah 30 orang siswa. Kelas X MIA 2 menggunakan prosedur praktikum yang biasa digunakan di sekolah. Instrumen perlakuan yang digunakan adalah silabus dan RPP dan untuk instrument tes digunakan 5 soal untuk kemampuan pemecahan masalah dan 10 soal untuk hasil belajar siswa. Hasil penelitian yang diperoleh adalah kemampuan pemecahan masalah Fisika pada kelas XI MIA 2 Setelah dilaksanakan pembelajaran dengan metode praktikum, kemampuan pemecahan masalah dan hasil belajar siswa meningkat. Hal ini ditunjukkan dengan: (1) Hasil pembelajaran menggunakan metode demonstrasi mengalami peningkatan dari siklus I siswa yang tidak lulus $70 \%$ dan lulus $30 \%$, pada siklus II siswa yang tidak lulus $25 \%$ dan lulus $75 \%$. Hal ini terjadi dikarenakan metode demonstrasi yang digunakan pada siklus I adalah metode demontrasi biasa dan pada siklus II menggunakan metode demonstrasi dengan prosedur berbeda. (2) Aspek pemecahan masalah sesuai indikator pemecahan masalah mengalami peningkatan yaitu aspek mengidentifikasi pada siklus I 43,52\% dan pada siklus II menjadi 72,53\%, aspek menerapkan strategi pada siklus I 56,42\% dan pada siklus II menjadi 77,63\%, aspek merumuskan masalah Fisika pada siklus I 33,90\% dan pada siklus II menjadi 76,72\%, aspek menginterpretasikan masalah Fisika pada siklus I 53,52\% dan pada siklus II menjadi 86,15\%.
\end{abstract}

Kata Kunci: Kemampuan Pemecahan masalah, Penelitian Tindakan Kelas, MAN Sipirok

\begin{abstract}
This study aims to improve the ability to solve physics problems and student learning outcomes in the materials of Straight Motion Kinematics with the initial ability to use ordinary practicum methods and practicum methods with different procedures. This research is a Classroom Action Research (CAR) with two cycles. The subject of this research is class X MIA 2 MAN Sipirok, each class totaling 30 students. Class X MIA 2 uses practicum procedures commonly used in schools. The treatment instruments used were syllabus and lesson plans, and for the test instrument used five questions for problem-solving skills and ten questions for student learning outcomes. The results obtained are the ability to solve physics problems in class XI MIA 2. After learning with practicum methods, the ability to solve problems and student learning outcomes increase. This is indicated by (1) Learning outcomes using the demonstration method have increased from cycle I students who did not pass $70 \%$ and passed $30 \%$, in cycle II students who did not pass $25 \%$ and passed $75 \%$. This happens because the demonstration method used in the first cycle is the usual demonstration method and in the second cycle uses a demonstration method with different procedures. (2) Aspect of problem-solving according to the indicator of problem-solving has increased namely identifying aspects in the first cycle of $43.52 \%$ and the second cycle to $72.53 \%$, aspects of implementing the strategy in the first cycle $56.42 \%$ and in the second cycle to $77.63 \%$, aspects of formulating Physics problems in the first cycle $33.90 \%$ and in the second cycle to $76.72 \%$, aspects of interpreting Physics problems in the first cycle $53.52 \%$ and in the second cycle to $86.15 \%$.
\end{abstract}

Keywords: Problem-solving ability, Classroom Action Research, MAN Sipirok

PeTeKa (Jurnal Penelitian Tindakan Kelas dan Pengembangan Pembelajaran) $\mid 9$ 
PeTeKa (Jurnal Penelitian Tindakan Kelas dan Pengembangan Pembelajaran)

Vol 2 No 1 Tahun 2019 Hal 9-13

\section{PENDAHULUAN}

Pendidikan merupakan salah satu sarana yang bertujuan untuk meningkatkan pengetahuan dan keterampilan manusia. Dimana pengetahuan dan keterampilan sangat dibutuhkan manusia untuk meningkatkan taraf hidupnya di masa depan. Menurut Sagala, (2013) Pendidikan dapat dimaknai sebagai proses mengubah tingkah laku anak didik agar menjadi manusia dewasa yang mampu hidup mandiri dan sebagai anggota masyarakat dalam lingkungan alam sekitar dimana individu itu berada.Pelajaran Fisika merupakan bagian dari ilmu pengetahuan alam (IPA) yang erat kaitannya dengan lingkungan makhluk hidup. Dalam pembelajaran Fisika dituntut penguasaan konsep dan cara pengembangan konsep tersebut. Materi dalam ilmu Fisika awalnya dikembangkan berdasarkan percobaan namun dalam perkembangannya kimia diperoleh dan dikembangkan melalui teori.

Menurut Edgar (dalam Dimyati dan Mudjiono 2009) mengemukakan bahwa belajar yang baik adalah belajar melalui pengalaman langsung. Dengan pengalaman langsung siswa akan lebih mudah memahami dan memecahkan permasalahan yang dihadapinya saat belajar. Dan itu dapat diperoleh melalui praktikum atau eksperimen. Menurut Daryanto (2013) guru merupakan bagian terpenting dalam proses belajar mengajar, baik dijalur pendidikan formal maupun informal. Guru yang profesional dituntut untuk berinovasi agar siswa dapat memahami materi yang diajarkan dan dapat diterapkan dalam kehidupan seharihari. Metode praktikum akan memperjelas teori ataupun konsep Fisika yang telah dijelaskan oleh guru. Penerapan metode praktikum akan membantu siswa lebih mudah memahami materi. Praktikum yang dilaksanakan dalam pembelajaran Fisika akan meningkatkan rasa ingin tahu siswa.
Akan tetapi seringkali praktikum yang dilaksanakan di sekolah adalah praktikum yang sangat sederhana. Jika praktikum yang dilaksanakan hanya sebatas melakukan praktikum saja maka motivasi siswa pun tidak terpacu sepenuhnya sehingga kemampuan pemecahan masalahnya pun tidak sepenuhnya pula dipergunakan.

Nastiti Sulistyowati (2012) "kemampuan pemecahan masalah merupakan indikator keberhasilan dalam pembelajaran”. Kemampuan pemecahan masalah kimia siswa dapat diterapkan melalui pelaksanaan praktikum dengan tingkat yang lebih tinggi dibandingkan praktikum yang biasa dilakukan di sekolah.

Berdasarkan hasil wawancara peneliti dengan guru Fisika di MAN Sipirok, beliau menjelaskan bahwa pembelajaran Fisika di MAN Sipirok, guru hanya menggunakan metode pembelajaran langsung seperti ceramah, penugasan, dan tanya jawab. Selain itu kegiatan praktikum di MAN Sipirok sangat jarang dilakukan karena alat-alat laboratorium yang kurang memadai, dan siswa lebih ditekankan untuk mengerti apa ilmu Fisika dan perhitungan dalam Fisika bukan bagaimana siswa dapat memahami ilmu Fisika dan penerapannya dalam kehidupan. Selain itu, pelaksanaan praktikum diluar ruang kelas menguras banyak waktu menyebabkan guru susah untuk mengkondusifkan proses belajar siswa.

Peneliti juga melakukan tes awal terhadap siswa dengan menyebarkan 6 pertanyaan tes kepada 30 orang siswa dengan Kriteria Ketuntasan Minimal (KKM) 68. Dari tes tersebut diperoleh bahwa 13 siswa atau $43 \%$ yang dapat mencapai Kriteria Ketuntasan Minimal (KKM). Berdasarkan data diatas dapat disimpulkan bahwa kemampuan pemecahan masalah Fisika siswa dalam menjawab soal dalam pembelajaran masih rendah. Rendahnya kemampuan pemecahan masalah Fisika siswa juga akan 
menyebabkan hasil belajar siswa yang rendah.

\section{METODE}

Jenis penelitian yang akan dilakukan adalah Penelitian Tindakan Kelas (Classroom Action Research) disingkat PTK. Penelitian tindakan kelas ini dilaksanakan di MAN Sipirok, Tahun Pelajaran 2018/2019.

Subjek penelitian adalah siswa kelas $\mathrm{X}$ MIA-2 Tahun Pelajaran 2018/2019 yang berjumlah 30 orang, terdiri dari 14 orang siswa laki-laki dan 16 orang siswa perempuan. Objek penelitian ini adalah pembelajaran dengan metode demonstrasi yang diterapkan dalam proses pembelajaran Fisika di kelas X MIA-2 Tahun Pelajaran 2018/2019 MAN Sipirok.

\section{Analisi data}

Menurut Hake (2002), data diolah menggunakan analisis statistik deskriptif, dengan langkah-langkah sebagai berikut:

1. Teknik yang digunakan untuk mengetahui peningkatan kemampuan pemecahan masalah Fisika dengan metode demonstrasi setelah pretest, postest siklus I, dan posttest siklus II dilaksanakan

2. Teknik yang digunakan untuk mengetahui peningkatan kemampuan pemecahan masalah siswa dan aktivitas guru dalam belajar Fisika yang didasarkan dengan metode demonstrasi diolah dengan cara Persentase aktivitas

$$
=\frac{\text { Jumlah skor yang dicapai }}{\text { Skor maksimum }} \times 100 \%
$$

3. Teknik yang digunakan untuk mengetahui respon siswa mengenai kemampuan pemecahan masalah setelah menggunakan metode demonstrasi dilaksanakan di kelas, diolah dengan cara menggunakan persamaan:

$$
\% \text { Skor }=\frac{\text { Jumlah shor setiap aspek }}{\text { jumlah skor maksimum agpek }} \times 100 \%
$$

4. Teknik yang digunakan untuk mengetahui adanya peningkatan kemampuan pemecahan masalah Fisika siswa melalui metode demonstrasi digunakan :

$$
\mathrm{N}-\text { gain }=\frac{s_{\text {past }}-s_{\text {pre }}}{s_{\text {maks }}-S_{P r e}} \times 100 \%
$$

\section{HASIL DAN PEMBAHASAN}

Berdasarkan hasil observasi awal dengan perolehan nilai siswa, nilai terendah 35,00 dan nilai tertinggi 66,50 dengan nilai rata-rata 52,34. Hanya dua orang siswa $(5,26 \%)$ yang memperoleh nilai di atas kriteria ketuntasan minimal (KKM) yang ditetapkan 80. Rendahnya hasil belajar Fisika siswa kelas MIA X-2 MAN Sipirok tidak terlepas dari proses belajar mengajar dan karakteristik siswa.

Proses belajar mengajar dapat memberikan hasil belajar siswa dengan baik apabila siswa diberikan kesempatan untuk menggunakan kemampuan berpikir kreatifnya. Karakteristik siswa kelas MIA X-2 MAN Sipirok Tahun Pelajaran 2018/2019, pada umumnya aktivitas belajarnya rendah, kemampuan matematika siswa juga rendah, kemampuan berpikir kreatif dalam menyelesaikan suatu masalah juga rendah. Pembelajaran Fisika menuntut siswa untuk melakukan aktivitas dengan cara mencari, memberikan pendapat dari informasi secara kreatif sehingga mereka dapat menyelesaikan persoalan baik di sekolah maupun di masyarakat.

\section{A. Data Siklus I}

Setiap siklus pada penelitian tindakan kelas terdiri dari 4 tahapan yaitu:

1. Perencanaan.

a) Melakukan analisis kurikulum untuk mengetahui kompetensi dasar yang akan disampaikan kepada siswa melalui metode demonstrasi 
PeTeKa (Jurnal Penelitian Tindakan Kelas dan Pengembangan Pembelajaran)

Vol 2 No 1 Tahun 2019 Hal 9 -13

b) Membuat rencana pelaksanaan pembelajaran dengan metode demonstrasi

c) Mengembangkan format format evaluasi.

d) Membuat instrument yang digunakan dalam pembelajaran dengan metode demonstrasi

2. Pelaksanaan

a) Memberikan soal postes untuk mengetahui kemampuan awal siswa

b) Menyajikan materi kinematika dengan menggunakan metode demonstrasi

c) Siswa diberikan kesempatan setelah penjelasan materi melalui metode demonstrasi

d) Guru memberi kesempatan kepada siswa untuk melaksanakan praktikum dengan metode demonstrasi

e) Guru memberikan soal pretes untuk melihat perubahan setelah dilaksanakan pembelajaran dengan metode demonstrasi.

3. Observasi dan Evaluasi

a) Kehadiran dan situasi kegiatan belajar-mengajar.

b) Antusias siswa dalam belajar dan melaksanakan praktikum.

c) Keaktifan siswa dalam memberikan pertanyaan/tanggapan pada pertanyaan guru.

d) Cara guru menyampaikan materi pelajaran.

e) Cara guru dalam membimbing siswa yang membutuhkan bimbingan.

4. Refleksi

Setelah dilaksanakan pembelajaran dengan metode demonstrasi, maka diperlukan refleksi terhadap pelaksanaan siklus I sebagai perbaikan untuk siklus II. Data kemampuan pemecahan masalah yang lulus sesuai KKM 80 sekitar $30 \%$, artinya lebih dari setengah siswa kurang mampu melaksanakan pembelajaran dengan pemecahan masalah.

Aspek pemecahan masalah untuk indikator aspek mengidentifikasi sekitar
43,52\%, aspek menerapkan strategi sekitar 56,42\%, aspek merumuskan masalah Fisika sekitar 33,90\%, aspek menginterpretasikan masalah Fisika sekitar 53,52\%. Setelah di lakukan tanya jawab baik dengan guru maupun siswa, ternyata metode yang digunakan sudah sering dikerjakan sehingga kurang menarik lagi, sehingga kemampuan pemecahan masalah siswa belum tampak.

\section{B. Data Siklus II}

Setelah dilakukan refleksi pada siklus I, ditemukan bahwa hasil yang diperoleh masih belum sesuai dengan yang diharapkan peneliti, sehingga penelitian dilanjutkan pada siklus II dengan tahapan sebagai berikut:

1. Perencanaan.

a. Membuat rencana pelaksanaan pembelajaran dengan metode demonstrasi tetapi dengan prosedur yang berbeda

b. Mengembangkan format format evaluasi.

c. Membuat instrument yang digunakan dalam pembelajaran dengan metode demonstrasi

2. Pelaksanaan

a. Menyajikan materi kinematika dengan menggunakan metode demonstrasi dengan prosedur yang berbeda

b. Siswa diberikan kesempatan setelah penjelasan materi melalui metode demonstrasi dengan prosedur yang berbeda

c. Guru memberi kesempatan kepada siswa untuk melaksanakan praktikum dengan metode demonstrasi dengan prosedur yang berbeda

d. Guru memberikan soal pretes untuk melihat perubahan setelah dilaksanakan pembelajaran dengan metode demonstrasi dengan prosedur yang berbeda

3. Observasi dan Evaluasi 
a. Kehadiran dan situasi kegiatan belajar-mengajar.

b. Antusias siswa dalam belajar dan melaksanakan praktikum.

c. Keaktifan siswa dalam memberikan pertanyaan/tanggapan pada pertanyaan guru.

d. Cara guru menyampaikan materi dan membimbing siswa yang membutuhkan bimbingan.

4. Refleksi

Setelah dilaksanakan pembelajaran pada siklus II, proses pembelajaran dengan menggunakan metode demonstrasi yang sebelumnya, diganti dengan metode demontrasi dengan prosedur yang berbeda. Hasilnya pada siklus II yang lulus sesuai KKM 80 sekitar $75 \%$ dan yang tidak lulus 25\%. Artinya hampir seluruh siswa mampu melaksanakan pembelajaran dan kemampuan pemecahan masalah nya meningkat.

Aspek pemecahan masalah sesuai indikator pemecahan masalah mengalami peningkatan yaitu aspek mengidentifikasi pada siklus I 43,52\% dan pada siklus II menjadi 72,53\%, aspek menerapkan strategi pada siklus I $56,42 \%$ dan pada siklus II menjadi 77,63\%, aspek merumuskan masalah Fisika pada siklus I 33,90\% dan pada siklus II menjadi 76,72\%, aspek menginterpretasikan masalah Fisika pada siklus I 53,52\% dan pada siklus II menjadi $86,15 \%$.

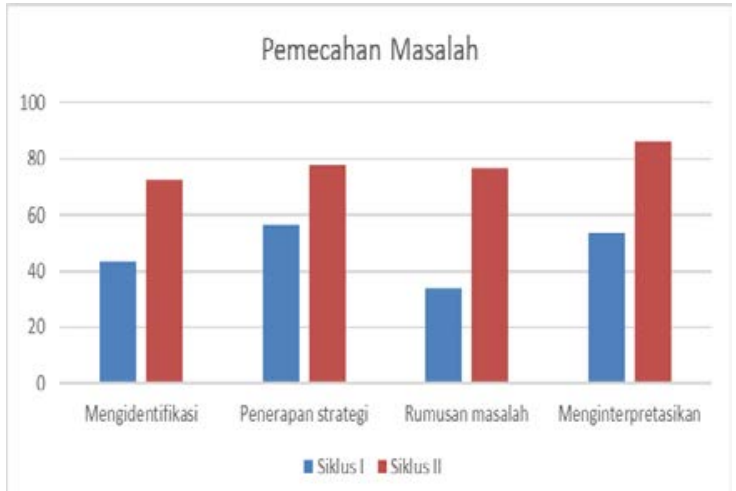

Tabel 1. Kemampuan Pemecahan Masalah Fisika Siswa Siklus I dan Siklus II

\section{SIMPULAN}

Dari hasil analisis data, maka dapat disimpulkan :

1) Hasil pembelajaran menggunakan metode demonstrasi mengalami peningkatan dari siklus I siswa yang tidak lulus 70\% dan lulus 30\%, pada siklus II siswa yang tidak lulus 25\% dan lulus 75\%. Hal ini terjadi dikarenakan metode demonstrasi yang digunakan pada siklus I adalah metode demontrasi biasa dan pada siklus II menggunakan metode demonstrasi dengan prosedur berbeda

2) Aspek pemecahan masalah sesuai indikator pemecahan masalah mengalami peningkatan yaitu aspek mengidentifikasi pada siklus I 43,52\% dan pada siklus II menjadi 72,53\%, aspek menerapkan strategi pada siklus I 56,42\% dan pada siklus II menjadi $77,63 \%$, aspek merumuskan masalah Fisika pada siklus I 33,90\% dan pada siklus II menjadi 76,72\%, aspek menginterpretasikan masalah Fisika pada siklus I $53,52 \%$ dan pada siklus II menjadi 86,15\%.

\section{DAFTAR PUSTAKA}

Daryanto. 2013.2 Media Pembelajaran.Gava Media: Yogyakarta.

Dimyati dan Mudjiono. 2006. Belajar dan Pembelajaran. Jakarta: Rineka Cipta.

Hake, R.R. 2002. Analyzing Change/Gain Scores. Tersedia di http://www. physics.

indiana.edu/ sdi/AnalyzingChange -Gain. pdf diakses 17 Juni 2019.

Sagala, Syaiful. 2013. Konsep dan Makna Pembelajaran. Bandung: Alfabeta.

Sulistyowati, Nastiti .2012. Efektivitas Model Pembelajaran Guided Discovery Learning Terhadap Kemampuan Pemecahaan Masalah Kimia. Jurnal Jurusan Kimia. 2(1). 